\title{
EMODnet Geology: digital geological maps of European seas
}

\author{
Fiorentino A. , Battaglini L., Conti M., D’Angelo S. \& Innocenti C. \\ ${ }^{a}$ Geological Survey of Italy - ISPRA, firstname.lastname@isprambiente.it \\ * Andrea Fiorentino, ISPRA, Via Vitaliano Brancati, 48 - 00144 Roma, Italy
}

Keywords: EMODnet, marine geology, digital map, European seas

\begin{abstract}
:
The European Marine Observation and Data Network (EMODnet) is a Project aimed at the collection and harmonization in European Seas of existing data, to be represented on digital maps freely available through a dedicated portal (https://www.emodnet.eu/en). It is subdivided into Lots concerning Bathymetry, Geology, Biology, Chemistry, Physics, Seabed Habitats and Human activities. Data displayed on the Portal are harmonized at different scales.
\end{abstract}

The EMODnet Geology Lot is realized by a Consortium of European Geological Surveys covering all of the European Seas. It includes information on seafloor sediments grainsize, sedimentation rates, Quaternary geology, pre-Quaternary geology and stratigraphy, geomorphology, coastal behaviour, geological events, mineral resources.

The sources of data are all pre-existing data in literature which also include cartography, databases, national and European projects. All these data were processed in order to produce digital cartography distributed as WMS services on the EMODnet Geology Portal (http://www.emodnet-geology.eu/).

As partner of the EMODnet Geology Consortium, the Geological Survey of Italy provides data to the Project, mainly relying on the comprehensive database complementing the Italian Geological Maps at 1:50,000 scale realized within the CARG mapping Project. Moreover, the Geological Survey of Italy coordinates the "Geological events and probabilities" Work Package n.6 (WP6), which aims to identify and map significant geological events such as earthquakes, volcanic centers, submarine landslides, tsunamis, fluid emissions and Quaternary faults.

Geological events are collated into layers subdivided by type of event and organized as shapefiles according to their geometric primitives (polygons, points, lines). Each occurrence is complemented, where available, by a comprehensive and detailed pattern of Attributes for each feature in order to represent their diverse characteristics, deriving also from the different geological settings of European sea areas. Datasets are elaborated according to guidelines provided by the WP coordinator after thorough discussion with all partners, aimed at identifying parameters to be used to characterize events and addressed to achieve the best degree of harmonization and standardization according to the European INSPIRE Directive.

The realization of the digital cartography of WP6 has been divided into several phases:

- elaboration of Guidelines and preparation of the instructions and technical specifications on how to supply GIS layers; during this step the parameters that should be used to characterize events were identified together with any additional relevant information. Particular attention has been devoted to the definition of the Attribute tables

- $\quad$ systematic collection of basic data, visualization and identification of any area without data

- generalization. Maps are generalized at the scale of representation established for each phase of the Project. Datasets consist of shapefiles representing each type of event at 1:250,000 scale in EMODnet Geology 2 and at 1:100,000 scale and more detailed in the following phases

- harmonization of data according to the specifications contained in the guidelines

- data processing, compilation and structuring of shapefiles in European-wide layers

- $\quad$ update, correction and implementation of files after review by partners

The amount of existing data is considerable: 3,000 records of landslides occurrences, more than 1,000 volcanic structures, almost 3,500 fluid emission areas, more than 500 tsunami events and more than 15,000 records of 
Quaternary faults have been entered into the database. Concerning earthquakes a link is provided to the Seismic Portal (www.seismicportal.eu), although additional data (approximately 3,000 entries) have also been recorded.

Information gathered during the Project, including metadata, is displayed on the Portal. Each occurrence reported must be complemented by the appropriate reference; additional information, including the names of specific features, can also be provided if available.

Submarine slides have been characterized by type of movement, material involved (lithology), volume, thickness, slope, age and source area. Terms adopted for type description were mainly obtained from Varnes (1978) also cited in the INSPIRE data specification on Natural Risk Zones.

Volcanic centers were complemented by information on their morphological and activity types, age of activity, chemical composition, eruption frequency, height, volcanic district and the presence of fluid emissions. The Volcanic Explosivity Index (VEI) is also relevant, if available; in this case the age of its reference eruption is required (VEI age).

The layer regarding tsunamis was subdivided into two shapefiles, one reporting locations of events which originated a tsunami and another one reporting the coasts affected by a tsunami, to be compiled only in case of unknown origin. Attributes listed for tsunamis are: date, type, cause, run-up, intensity, affected coast.

Fluid emissions have been classified according to the process that generates them or based on the associated materials of geological or biological derivation. Morphological types have also been considered since features are related to erosional or depositional processes as well as to the composition and escaping mechanisms of the fluid.

Tectonics was also considered relevant for the Geological events WP. Only faults active during the Quaternary were taken into account. It is necessary to specify whether they are buried or crop out as well as their type and age. Most of the terms adopted are listed within the INSPIRE data specification on Geology.

Based on landslides data gathered within WP6 and on information available from the EMODnet Bathymetry Portal (https://www.emodnet-bathymetry.eu/), a map of susceptibility to submarine landslides has been developed using the maximum entropy model.

Interoperability of data was one of the objectives pursued by the Project, in order to provide more complete, correct and reliable information and facilitate the exchange and reuse of data even among non-homogeneous systems. Besides combining these harmonized and standardized datasets, it might be possible to develop additional thematic maps that could support further research, as well as the planning and management of submerged areas.

\section{References}

VARNES D.J. (1978) - Slope movement types and processes. In: SCHUSTER R.L. \& KRIZECK R.J. (Eds.) "Landslides, analysis and control". Washington Transportation Research Board, Spec. Rep., n 176, pp. 11-33. 